\title{
Accelerating the energy retrofit of commercial buildings using a database of energy efficiency performance
}

\author{
Sang Hoon Lee ${ }^{1}$, Tianzhen Hong ${ }^{1 *}$, Mary Ann Piette ${ }^{1}$, Geof Sawaya ${ }^{2}$, Yixing \\ Chen $^{1}$, Sarah C. Taylor-Lange ${ }^{1}$ \\ ${ }^{1}$ Building Technology and Urban Systems Division, \\ Lawrence Berkeley National Laboratory \\ One Cyclotron Road, Berkeley, CA 94720, United States \\ ${ }^{2}$ School of Computing \\ University of Utah \\ 50 S. Central Campus Drive, Room 3190 \\ Salt Lake City, UT 84112
}

Sang Hoon Lee (sanghlee@lbl.gov) (510) 486-5811

Tianzhen Hong (thong @ lbl.gov) (510) 486-7082

Mary Ann Piette (mapiette@lbl.gov) (510) 486-7082

Geof Sawaya (sawaya@cs.utah.edu) (510) 318-4543

Yixing Chen (yixingchen@lbl.gov) (510) 486-5297

Sarah C Taylor-Lange (sctaylorlange@lbl.gov) (510) 486-4691

* Corresponding Author: Tianzhen Hong (thong@lbl.gov) (510) 486-7082 


\section{Abstract}

Small and medium-sized commercial buildings can be retrofitted to significantly reduce their energy use, however it is a huge challenge as owners usually lack of the expertise and resources to conduct detailed on-site energy audit to identify and evaluate cost-effective energy technologies. This study presents a database of energy efficiency performance (DEEP) that provides a direct resource for quick retrofit analysis of commercial buildings. DEEP, compiled from the results of about ten million EnergyPlus simulations, enables an easy screening of energy conservation measures (ECMs) and retrofit analysis. The simulations utilize prototype models representative of small and mid-size offices and retails in California climates. In the formulation of DEEP, large scale EnergyPlus simulations were conducted on high performance computing clusters to evaluate hundreds of individual and packaged ECMs covering envelope, lighting, heating, ventilation, air-conditioning, plug-loads, and service hot water. The architecture and simulation environment to create DEEP is flexible and can expand to cover additional building types, additional climates, and new ECMs. In this study DEEP is integrated into a web-based retrofit toolkit, the Commercial Building Energy Saver, which provides a platform for energy retrofit decision making by querying DEEP and unearthing recommended ECMs, their estimated energy savings and financial payback.

Keywords: High Performance Computing, EnergyPlus, Building Simulation, Energy Conservation Measure, Energy Modelling, Retrofit 


\section{Introduction}

Buildings consume $40 \%$ of the total primary energy in the United States [1]. Small and medium commercial buildings smaller than $50,000 \mathrm{ft}^{2}\left(4,647 \mathrm{~m}^{2}\right)$ represent $95 \%$ of the number of commercial buildings, and consume $47 \%$ of the total energy of the commercial buildings excluding malls [2]. Energy efficient technologies can reduce energy use in buildings, save money, and mitigate the environmental impacts of energy use such as global climate change. More than $45 \%$ savings can be realized in small and medium commercial buildings from cost effective retrofits [2]. To improve building energy efficiency, governmental retrofit guidelines and utility incentive programs promote retrofit activities in the buildings sector. However, it is not easy for building owners and energy managers to obtain tangible information on the applicability of retrofit technologies, nor how much energy or cost can be saved. Although a wide range of technologies are readily available, Ma et al. pointed out that the main challenge still lies in how to identify the most effective retrofit measures to meet building owner's investment criteria [3].

Many building owners of large commercial buildings use Energy Service Companies (ESCOs) to conduct energy audits to identify effective energy retrofit and management strategies. Energy audits provide a summary of potential retrofit measures or operational improvements coupled with building energy performance evaluations, to improve energy efficiency. Detailed energy audits often involve elaborate data collection over long time durations, the development and calibration of an energy model, and iterative simulations for detailed analysis [4]. 
Beyond energy audits, data-driven analytics enable energy retrofits to help operational improvements. The data-driven approach, powered by measured energy use data at short time intervals, enriches analysis for energy profiling and diagnostics. For example, the 5-minute interval data of chiller power was used to detect cycling of chillers which would not be possible using hourly or larger interval data. Smart meters are adopted rapidly, and use of the interval electric use data fills information gaps to inform operational energy saving strategies that cannot be realized with the simulation-based retrofit analysis [5].

Unique engineering expertise is required to characterize building equipment and systems for the development and configuration of simulation models, which can require days or weeks of work depending upon model complexity and the amount of parametric simulations. Building owners and stakeholders of small and medium-sized buildings (SMBs) usually lack the resources to conduct detailed retrofit analysis. Instead they tend to rely on simple assessments, using ruleof-thumb calculations for retrofit energy and cost savings. Although initially inexpensive, this approach lacks accuracy, resulting in retrofit strategies for isolated measures without consideration of interactive effects between measures. Therefore, the potential energy savings or economic benefits may not be maximized [6].

Alternatively, a large set of packaged simulations performed by experts will provide an easy and authentic solution for quick retrofit analysis [7]. Although a pre-simulated approach comes with limitations, such as the use of prototypes to represent actual buildings which may not match the actual geometry of the buildings, it provides an immediate and reliable energy assessment. In the last five years, some of the pre-simulated databases developed include the U.S. Department of Energy (DOE)'s 179D easy calculator [8], Energy Impact Illinois' 
EnCompass [9], Database for Energy Efficient Resources (DEER) (CEC 2014c), and LBNL's Commercial Building Analysis Tool (COMBAT) for Energy-Efficiency Retrofit [10]. The DOE's 179D energy calculator supports the tax deduction program Section 179D Energy Policy Act [11] and determines tax deduction eligibility for energy efficiency improvements to commercial buildings. Pre-simulated data are used to determine partial and interim compliance and to avoid high costs associated with simulations. EnCompass searches 278,000 energy models of large Chicago office buildings to find a best-fit baseline energy model from the pre-simulated database, and presents the energy data with energy saving opportunities and retrofit recommendations. DEER provides a list of retrofit recommendations and associated energy savings. Using batch mode analysis, data from roughly 65,000 eQuest pre-simulation runs integrates retrofit measures with a subset of the California commercial buildings. COMBAT uses prototype building models for different commercial building types in China. The prototype models using EnergyPlus were applied to a large number of energy conservation measures (ECMs) in major Chinese cities, creating a pre-simulated database. Recent advances in computing environments have enabled the execution of large scale building energy simulations for database creation, considering various energy-related analysis including model calibration, energy optimization, and zero-energy building design. Typically building owners and facility managers use the pre-simulated databases to screen potential measures as a starting point of retrofit.

High performance computing (HPC) brings new opportunities to accelerate energy retrofit assessment of commercial buildings through the development of database creation comprised of energy efficiency performance parameters derived from simulations. Existing 
retrofit tools allow for parametric runs to explore alternative design options. The OpenStudio Parametric Analysis Tool (PAT) [12] and jEPlus [13] provide a parametric shell to define parameter values for different design options and call EnergyPlus to conduct multiple, automated simulations. EnergyPlus, with OpenStudio Software Development Kit (SDK) and PAT, is well suited for large-scale, whole building energy simulations in an HPC environment. OpenStudio SDK enables effective EnergyPlus simulations by applying ECMs from a Building Component Library (BCL). PAT conducts cloud-based simulations of multiple OpenStudio models that are parametrically related to a baseline model. Hale $e t$ al. described a cloud-based energy simulation method that uses OpenStudio for model calibration in parallel computing using the Amazon Elastic Computer Cloud service [14]. This method highlighted multi-nodal computing architecture for model parameterizations used for calibration, which can potentially recommend combinations of retrofit energy saving measures with the calibrated model. Naboni et al. identified an open-source and cloud-based service that can be applied in architectural and engineering practices, spreading the use of parametric energy simulation [15]. A parametric shell for EnergyPlus, jEPlus handles simulation jobs executed on the VENUS-C cloud infrastructure VENUS-C (Virtual multidisciplinary EnviroNments Using Cloud infrastructures) provides a scalable and flexible virtual infrastructure empowering easy deployment [16]. The use of the cloud-based HPC reduces the computational time for parametric simulations allowing for evaluation of many more measures and their integrative effect, thus contributing to a potentially higher degree of building energy savings, relative to conventional design processes. The input to EnergyPlus can often extend to the order of a few thousand parameters that have to be calibrated manually by an expert for realistic energy modelling. This makes the process challenging and 
expensive thereby making building energy modelling sometimes unfeasible for smaller projects. Auto-tune research employs machine-learning algorithms to generate energy models for the different kinds of standard reference buildings in the U.S. building stock. Sanyal et al. explored the computational challenge of using supercomputers to conduct millions of EnergyPlus simulations on supercomputers that were subsequently used to train machine learning algorithms to generate parametric space and the variety of building locations and types [17].

There are other ways of conducting massive simulations using distributed computing resources such as HTCondor and CometCloud that facilitate task processing. High-throughput computing (HTC) Condor is widely used by researchers to employ the full potential of distributed computers for computational intensive tasks, such as simulations and calculations [18]. Condor is an open-source HTC workload management software for a cluster of distributed computer resources. As an example, the HTCondor system was used to optimize building energy design by exploring the computing performance of distributed computing resources [19]. Another use demonstrated by Tian and de Wilde was HTC using the Condor software package to evaluate building thermal energy performance, and they conducted simulations of many independent EnergyPlus models under probabilistic climate conditions by harnessing the processing power of idle desktop computers [20]. CometCloud [21] is an autonomic computing engine based on the Comet [22] decentralized coordination substrate, and supports highly heterogeneous and dynamic cloud or grid infrastructures. Kim and Parashar enabled the integration of public/private clouds and autonomic cloudbursts to address extreme requirements such as heterogeneous and dynamic workloads and spikes in demands [21]. 
With these recent advancements in the computing environment, the execution of large scale simulations for database development provides users with new resources to conduct quick and reliable retrofit assessments. In an effort to promote retrofit activities, there is a strong and growing need for the systematic establishment of energy performance databases. This paper presents the framework used to establish the pre-simulated the Database of Energy Efficiency Performance (DEEP) which describes building energy efficiency performance parameters from an HPC-set of building energy simulations. An example retrofit analysis is provided showing how DEEP can be used. The retrofit analysis, powered by the pre-simulated database, can be easily conducted by building owners, facility managers, and engineers in SMB sector and can substitute, within reason, time-consuming and expensive energy audits.

\section{The Database of Energy Efficiency Performance (DEEP)}

DEEP is an SQL database and contains input parameters of prototype building models and the simulation results from energy models. Currently DEEP includes data for a wide range of vintages, California climate zones, building types (e.g. small and medium offices, retail, and mixed-use buildings), a large set of ECMs, as well as the energy performance data considering not only individual measures but also the interactive effects between multiple individual measures.

The energy data for DEEP are compiled evaluating results from 10 million simulation parametric runs using EnergyPlus. EnergyPlus is the U.S. DOE flagship building energy modelling engine (energyplus.net). The large number of simulations is made possible by using an HPC parallel cluster with hundreds of thousands of cores. Figure 1 and 2 shows the overview 
and components that went into the creation of DEEP. Due to its flexibility in simulation and database structure, DEEP can be easily expanded to cover more building types, more climates, and more energy conservation measures. A section of the paper is dedicated to describing the details of using HPC clusters at the U.S. National Energy Research Scientific Computing (NERSC) center for large-scale simulations to maximize computing efficiency.

Figure 1 Overview of DEEP

Figure 2 Components of DEEP

DEEP serves as a database for screening and evaluating retrofit measures for commercial buildings and is made available to the public via a web-based Commercial Building Energy Saver (CBES) Toolkit. The CBES toolkit enables a quick and reliable retrofit analysis with the results including:

- Annual electricity and natural gas consumption

- $\quad$ Monthly energy consumption in site energy (electricity and natural gas)

- Monthly energy consumption broken down into end uses, such as lighting, cooling, heating, domestic hot water, electric equipment, fan, and pump.

- $\quad$ Peak electrical power demand and the time of the year

- $\quad$ HVAC system capacities

- $\quad$ Energy costs, retrofit investment costs and payback years

DEEP helps guide the selection of building retrofits to reduce energy use and carbon emissions by providing readily available energy saving by retrofit measures. DEEP is designed for use by building owners, facility managers, engineers, architects, and energy auditors. 


\section{The technical aspects of DEEP}

\subsection{Prototype buildings}

The essential task in establishing DEEP is to develop prototype buildings to be used in simulation. The prototype models represent small and medium-size office and retail buildings in California. Table 1 summarizes the key features of the prototype building models for seven building types, six vintages, and 16 climate zones in California [23].

Table 1 Description of the prototype buildings

The prototype building models are built to comply with the requirements of historical versions of the California Building Energy Efficiency Standards, Title 24 [24]. These prototypes are based on the energy models of the Database for Energy Efficient Resources (DEER) [25] and the DOE reference buildings [26], with detailed specifications listed in Table 2. Further details of the prototype buildings are described in the functional specification document [27].

Table 2 Prototype development sources

Added to the prototype building models, upgrades made to the building systems are considered when establishing the baseline building models. This effort provides a model which is a better representation of the actual building and considers asset changes during the buildings' life cycle. For example, most buildings in California were built decades ago and many building owners have replaced building systems such as lighting, cooling, heating, electrical appliances, and windows with upgraded efficiency levels matching that of Title 24 standards (at the time of 
the upgrade). Table 3 shows a sample list of efficiency requirements for different vintages and climate zones from Title 24.

Table 3 A sample list of Title 24 efficiency requirements

To enhance the value of the pre-simulated database and to provide a more realistic representation of existing buildings, the pre-simulation energy models consider the available upgrade options:

- Lighting systems:

$\circ$ Upgraded to T8 lamps, meeting the requirements of Title 24-2005 of lighting power density of $1.1 \mathrm{~W} / \mathrm{ft}^{2}\left(11.8 \mathrm{~W} / \mathrm{m}^{2}\right)$

- Upgraded to T5 lamps, meeting the requirements of Title 24-2013 of lighting power density of $0.8 \mathrm{~W} / \mathrm{ft}^{2}\left(8.6 \mathrm{~W} / \mathrm{m}^{2}\right)$

- Glazing systems:

○ Windows upgraded to meet Title 24-2005 requirements

○ Windows upgraded to meet Title 24-2013 requirements

- Cooling systems:

- Rated efficiency upgraded to Energy Efficiency Ratio (EER) 10.5, meeting Title 242005 requirements

○ Rated efficiency upgraded to EER 11.5, meeting Title 24-2013 requirements

- Heating systems

○ Rated efficiency upgraded to Annual Fuel Utilization Efficiency (AFUE) 90, for condensing furnaces or boilers

\subsection{Energy Conservation Measures (ECMs)}

DEEP was established using baseline building models and energy efficiency measures that consider the applicable local climate conditions for the building systems including envelope, heating, ventilation, and air conditioning (HVAC), as well as non-climate related systems such as lighting, plug-loads, and domestic hot water. The energy conservation measure database includes detailed technical specification and modelling methods for each measure. The measures are 
compiled from various sources including the Advanced Energy Retrofit Guide for offices and retails [28,29], DEER [25], Small HVAC System Design Guide [30], Advanced Energy Design Guide for Small Commercial Buildings [31], Home Energy Saver Measures database [32].

There are two distinct categories of measures from a cost perspective: hardware or software technology retrofits, or no-cost/low costs measures. Measures that incur retrofit hardware or software capital costs involve the replacement of equipment or building components in order to improve performance. No-cost/low-cost measures involve minimal cost investment and achieve energy savings by implementing more efficient operation and maintenance practices. Examples of the later include adjusting the temperature set-point to minimize mechanical heating and cooling, or scheduling equipment maintenance to optimize operation conditions. In addition to the technical details, the measure database provides cost data for materials and labor. These cost data enrich the analysis by providing economic metrics such as the total cost and simple payback time (in years) for a retrofit. This enables users with additional information in deciding retrofit strategies. The economic analysis reflects the local conditions of costs using the RSMeans location factor to adjust the measures cost. The full list of measures are described in a measure data compilation report [33]. Units are displayed in the Inch-Pound system for the database development. To convert to the International System of Units, 1 square meter $\left(\mathrm{m}^{2}\right)$ is 10.76 square feet $\left(\mathrm{ft}^{2}\right)$, R-value of 1 in $\mathrm{m}^{2} \mathrm{~K} / \mathrm{W}$ is 0.176 in $\mathrm{BTU} /\left(\mathrm{h} \cdot{ }^{\circ} \mathrm{F} \cdot \mathrm{ft}^{2}\right), \mathrm{U}$-value of 1 in $\mathrm{W} /$ $\left(\mathrm{m}^{2} \mathrm{~K}\right)$ is $5.678 \mathrm{in} \mathrm{h} \cdot{ }^{\circ} \mathrm{F} \cdot \mathrm{ft}^{2} / \mathrm{BTU}$. A sample list is shown in Table 4.

Table 4 A sample list of energy conservation measures 


\section{Methods and process to manage large-scale simulation}

\subsection{Control of parametric runs}

DEEP contains the energy simulation results from a set of baseline building models and retrofits from both individual measures and packages of measures. We performed about 10 million simulation runs covering the scenarios listed in Table 5.

Table 5 Constituents used in creating the total number of simulation runs

Figure 3 The framework used for establishing DEEP

Figure 3 illustrates the framework used to conduct the simulation. The process starts with preparing seed Input Data Files (IDF), which are unique per building type. Next, control files manage the generation of IDFs reflecting parameters for different vintages, climate zones, and retrofit measures. When generating IDFs, ASHRAE design conditions Design Day Data (DDY) are embedded for each climate location. This enriches the simulation results and considers HVAC system capacity, potentially reducing peak cooling and heating loads from retrofits. Next, the codes generate IDFs and link the climate zone specific EnergyPlus Weather (EPW) files needed for simulations.

\subsection{Parametric runs using NERSC clusters}

One challenge in establishing DEEP lies in the number of simulation runs required and the inherent time and cost associated with the computing environment. On a typical computer, an individual simulation run can require several minutes depending upon which building type and features are implemented. If we use a single desktop computer with four cores (about $2.7 \mathrm{GHz}$ ), 
it would take roughly ten years to run ten million simulations, making the job almost impossible to complete with a normal, common computing environment. To overcome this issue, high performance computing clusters, specifically the Hopper system at the National Energy Research Scientific Computing (NERSC) center at the Lawrence Berkeley National Laboratory (LBNL), were used. NERSC is one of the largest facilities in the world to provide computational resources to accelerate scientific energy research through advanced computation.

The process to configure the simulations on the Hopper system include (1) installing the required applications (e.g. EnergyPlus and Ruby), (2) developing codes for assigning simulation parameters for retrofit measures, (3) generating IDFs, allocating simulation jobs, and (4) consolidating simulation outputs to a comma separated value (CSV) file. This CVS file is imported into SQlite database for DEEP. Some of the more notable files required to obtain the energy results data from the initial inputs, consist of seed IDFs, EPW files, and supplementary EnergyPlus object files. The ControlVect files define objects with a list of values that are systematically perturbed to generate a number of IDF specifications to represent energy models for prototype buildings of different types, vintages, and climates allowing various retrofit measures. These ControlVect functions determine the value of any specified IDF file object such as HVAC efficiency, construction materials, and window performance.

The objective was to create an infrastructure of software, maximizing the utilization of NERSC Hopper XE6 computing resource, to keep the processing elements continually filled with individual and short lived EnergyPlus simulations. In doing so, the processes were tailored to fit the ALPS (Application Level Process Scheduler) system, with a typical workload consisting of a singular long running simulation. In general, this protocol was manageable for the 
job scheduler, the application level placement scheduler, the networked file system, and the service/system command provider.

In contrast, parametric simulations, consisting of millions of little (short lived, serial, and with minimal memory footprint) simulations, proved more challenging. Tens of thousands of simulations running concurrently in a system with a sparse percentage of machine nodes proved challenging due to limited file accesses for both job specific files and common tools, such as system commands. To reduce the impact on the entire cluster system and ensure reasonable performance for our Massively Parallel Processing (MPP) hours, an additional level of command and data caching was required. MPP represents a type of computing that uses many separate CPUs running in parallel to execute a single program.

All processing steps, including generating the input data, conducting the simulations, and collecting the outputs, were conducted in parallel to make the best use of the 24 cores available in NERSC Hopper compute nodes. The following naming notation is used in order to concisely and accurately describe the semantics of the processes. An EnergyPlus input data file consists of a collection of EnergyPlus objects, a set of elements each of which has a name and contains a list of values as shown in Step 1 and Step 2.

$$
\begin{aligned}
& i d f_{-} o b j:=\left(\text { name },\left(v_{1}, v_{2}, \ldots, v_{n}\right)\right) \quad(\text { Step } 1) \\
& i d f=\left(i d f_{o b j_{1}}, i d f_{o b j_{2}}, \ldots, i d f_{o b j_{m}}\right)(\text { Step } 2)
\end{aligned}
$$

The seed IDF files are integrated with the climate specific design day data (DDY) file, prior to processing the ControlVect file. The ControlVect file in Ruby code controls the generation of the parametric IDFs specifying a collection of input variables and EnergyPlus 
objects. A collection of variables, $p_{\text {_ vars, }}$ each of which is a tuple of a name and set of values to set. A collection of interface objects, $c$ _idf_objs, which are a tuple consisting of an IDF object name, an IDF object field number. Functions taking an ivect producing a singular value as shown in Step 3 to Step 6.

p_var: $=\left(\right.$ name, plist $\left.:=\left\{v_{1}, v_{2}, \ldots, v_{x}\right\}\right)$

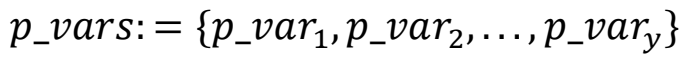

$c v_{-} i d f_{-}$obj: $=($name, field num $f(\quad):$ ivect $\rightarrow$ val $)$

$c v_{-} i d f_{-} o b j s:=\left\{c v_{-} i d f_{-} o b j_{1}, c v_{-} i d f_{-} o b j_{2}, \ldots, c v_{-} i d f_{-} o b j_{Z}\right\}$

A first step in generating a multitude of IDF input files is to generate a set of value vectors from a new collection of IDFs. The process consists of building the set of all the plists to produce the input vectors as in Steps 7 and 8.

$\left\{\right.$ ivects $\left.\mid p \_v a r_{1} . p l i s t \times p \_v a r_{2} . p l i s t \times \ldots \times p \_v a r_{i}\right\} \quad($ Step 7$)$

ivects $:=\left\{\left(c v_{1}, c v_{2}, \ldots, c v_{n}\right)_{1},\left(c v_{1}, c v_{2}, \ldots, c v_{n}\right)_{2}, \ldots,\left(c v_{1}, c v_{2}, \ldots, c v_{n}\right)_{\prod_{i=1}^{n} \mid \text { pvar }}\right.$. plist $\mid$ Step 8)

Once the set of ivects has been generated, these values are applied as one vector to each IDF using the functions provided in the $c v_{-} i d f \_o b j s$. List indexing, such that so[1] yields the element list from the IDF object and the expression, so[1][0..x], refers to the elements from 0 to $x$, exclusively. Thus, so[1][x..] accesses the object elements from $x$ to end, with so[1][so[1].len] returning nil.

Once the IDF files are generated, they are evenly divided into compute node partitions and packaged to be copied to the compute nodes. In addition to the collection of inputs for the simulations, each compute node gets a cache of software, including required Linux system commands. These commands and libraries, along with the EnergyPlus binary, are 'installed' by 
unpacking them into a created top level folder in each compute node's temp directory (which is a mounted ram disk) and by setting the shared library path appropriately. By doing this, simulations runs and various management procedures are executed without burdening the network or any support node. The simulations are run by a process manager on each compute node. This set of process managers, called the Message Passing Interface (MPI), communicates via a periodic heartbeat in order to monitor the health and the progress of the cluster wide simulations. It also launches simulations to run on the local cores, periodically checking each for termination and launching new simulations in order to minimize core idle time. The heartbeat is an MPI collective operation, MPI_All_reduce, that determines the internode state of the job. Each node must wait for the entire job to complete before calling MPI_Finalize. Also, if a failure is detected, all compute nodes terminate.

The development of the simulation environment at NERSC used 2.5 million MPP hours

for testing codes, debugging, optimizing the simulation speed, and producing data. Using NERSC, 10 million simulation runs requires an execution time of 240 clock hours (10 days) including time for generating IDFs, simulation running, and consolidating outputs.

\section{Integration of DEEP with an energy retrofit application}

DEEP is a stand-alone database that can be integrated into energy retrofit analysis tools. In the future, DEEP will feed into DEnCity, DOE's Energy City [7], which is a planned public resource to support the design and retrofit of energy efficient buildings. DEnCity integrates large-scale energy data for multipurpose, open, and dynamic database leveraging. DEnCity uses a diverse source of existing simulation data to help building owners, designers and engineers improve the energy efficiency of buildings. 
DEEP is integrated with the CBES toolkit. The CBES toolkit analyses the energy performance of buildings pre- and post-retrofit, in conjunction with user input data, to identify recommended retrofit measures, energy savings and economic solutions for selected energy measures. The toolkit provides energy benchmarking and three levels of retrofit analysis depending upon the intricacy of the input data provided. The energy benchmarking is provided using Energy Star [34] Portfolio Manager and EnergyIQ [35] via their software Application Programming Interface (API). The Level 1 option provides no- or low-cost improvement analysis and is performed to identify potential building operation problems or unexpected changes in energy use patterns using statistical analysis of the building's electric load. The Level 2 option provides a preliminary retrofit analysis with a quick look-up table style to evaluate retrofit measures, their energy and cost benefits. Level 2 utilizes DEEP to evaluate ECMs encompassing building envelope, lighting, HVAC, domestic water heating, plug-loads, and operation and maintenance. Lastly, Level 3 provides a detailed retrofit analysis, with on-demand energy simulations that calculate the energy performance of the building with user configurable ECMs. Figure 4 presents a schematic highlighting the features of the CBES toolkit.

\section{Figure 4 Features of CBES Toolkit}

The CBES toolkit provides its analytics through APIs and a web portal. The web portal is easy and powerful to use for various audience, including building owners, building operators, facility managers, engineers, and energy consultants, providing options for a wide range of expertise and available data. The CBES toolkit APIs can be potentially integrated into utility 
portals or other third-party software that provide energy retrofit incentives and energy and cost savings evaluations. The CBES Toolkit enables the acceleration of energy retrofits of SMBs.

This section provides an example of how to use DEEP for a preliminary retrofit analysis of a small office building, taking advantage of the CBES web app. In this example, a hypothetical building owner has a one-story small office building located in San Francisco, California. The building owner would like to benchmark the building's energy consumption with other peer buildings in California and nation-wide. The owner's objective is to explore different energy retrofit options to reduce the energy cost of his building. Additionally, the building owner had previously upgraded the lighting system in the building to reduce consumption from 2.0 to $1.1 \mathrm{~W} / \mathrm{ft}^{2}\left(21.5\right.$ to $\left.11.8 \mathrm{~W} / \mathrm{m}^{2}\right)$. Today, he has a total of $\$ 15,000$ to invest in his retrofit project. His primary goal is to save energy cost and he wants the payback period to be less than three years. He would like to conduct a preliminary retrofit analysis to identify what retrofit options are available. Therefore, he uses the benchmarking and Level 2 features, built upon DEEP, of the CBES toolkit for a quick estimate of retrofit potentials. The available input data are summarized in Tables 6 and 7.

Table 6 Input parameters for the CBES toolkit benchmarking and Level 2 analysis

Table 7 Monthly electricity and natural gas usage

The annual energy use intensity of the building is $204 \mathrm{kWh} / \mathrm{m}^{2}$. The benchmarking results show an Energy Star score of 17, indicating the need for an energy retrofit. The CBES toolkit uses the Energy Star Portfolio Manager API to provide the Energy Star score of a building. The Energy Star Portfolio Manager is an online tool developed by the US Environmental Protection Agency to benchmark the energy consumption of buildings. The ENERGY STAR score is a 
measure of how well a building is performing relative to peer buildings following normalization for climate and operational characteristics [34]. A 1 to 100 scale (1 representing poor performance and 100 representing best performance) is used, with 50 indicating the national median level, taking into account its size, location, and operating parameters. The EnergyIQ benchmarking result shows that the site energy consumed for a typical building, similar to the user's building is $101 \mathrm{kWh} / \mathrm{m}^{2}$ [median], with a range of 71 to $289 \mathrm{kWh} / \mathrm{m}^{2}$ [5th to $95 \mathrm{th}$ percentiles]. The CBES toolkit uses EnergyIQ API, a tool for building energy benchmarking of non-residential buildings using the CEUS database for US California commercial buildings. The EnergyIQ provides statistical energy consumption information of peer buildings including the median energy value and energy distribution [35]. The results suggest that the energy performance of the building is poor.

With the basic building information, the CBES toolkit provides the energy retrofit feedback by querying DEEP and unearthing the recommended ECMs that meet the building owner's investment criteria, budget and payback years. The ECMs are ranked based on the investment criteria as options of (1) maximizing energy cost saving, (2) maximizing energy saving, (3) minimizing $\mathrm{CO}_{2}$ emissions, (4) minimizing investment cost, and (5) minimizing payback period. Table 8 tabulates the retrofit analysis results that meet the investment preference (a total budget of $\$ 15,000$, a primary goal to save energy cost, and a payback period less than three years). Matching this criteria, the ECM measures selected are ECM 1 (lighting), ECM 12 (HVAC air economizer) and ECM 15 (plug loads). For each ECM, the results show the description of the measure, its potential indoor environmental impact (IEQ) during retrofit, investment cost, energy use and cost, as well as energy use savings and energy cost savings 
compared with the baseline building before retrofit. The combination of adding an economizer and changing the plug load usage results in the lowest electricity use, electricity demand charge, energy cost, and maximal $\mathrm{CO}_{2}$ emissions reduction.

Table 8 CBES Level 2 Preliminary Retrofit Analysis Results using DEEP

\section{Discussion}

The establishment of DEEP was made possible by using HPC clusters that enabled parallel simulations with millions of MPP hours. This paper describes the procedure to enable the colossal amount simulations with maximized computing efficiency. Definitely this process was a nontrivial effort considering the quantity of simulation runs needed to provide comprehensive SMB coverage. This database could not be realized without recent advancements in building energy simulation and the computing environment. As this environment further develops, the ability to expand capabilities to cover more building types, locations, and ECMs with less hassle, will exist.

Although DEEP enables a quick retrofit analysis by screening ECMs based on building type, built year, and climate location, there are some limitations associated with using pre-defined analysis. One weakness occurs due to the fact that the pre-simulated database utilizes prototype buildings which often do not exactly match the geometry of the user's building. Although reference energy models are widely used to analyse energy performance, the energy analysis is limited to the building stock description. Additionally, the results in DEEP are from the simulation results of EnergyPlus models which have not been validated against results from actual retrofit projects. Future work will include validation of some of the DEEP results. 
Another limitation lies in the pre-determined ECMs that are integrated into the reference energy models. Although DEEP covers comprehensive, market-available, and readily applicable technologies recommended for cost effective retrofits, underlying assumptions for efficiency values and specifications for each of ECMs are pre-set. Thus, the energy savings for the selected measure indicates approximate savings for the specific technology applied to a prototype building. DEEP covers packages of measures to evaluate the integrated effects of ECMs. However, as with the single measure analysis, the packaged measure analysis does not allow for user defined packages.

Despite these limitations, DEEP plays a large role in motivating SMB retrofits. Currently DEEP is embedded in the CBES toolkit (Section 5 and Section 6) to provide preliminary retrofit analysis, including a recommended list of ECMs that meet a user's retrofit investment criteria and provides potential energy cost savings and estimated investment payback years. This preliminary retrofit analysis serves to motivate users to try the detailed retrofit analysis ensuring more accurate results. CBES is capable of transferring the recommended measures from DEEP into more advanced the detailed energy modeling using real-time EnergyPlus simulations. This seamless transition plays a critical role in accelerating the retrofit activities in SMBs.

\section{Conclusions}

DEEP, an SQL database of energy efficiency retrofit results for small and medium-sized commercial buildings, is compiled from results of 10 million EnergyPlus simulations pre-run on super computers. DEEP covers seven building types in six vintages and sixteen California climates. DEEP enables, as a lookup table, a quick and reliable retrofit assessment of small and medium-size office and retail buildings, that avoid time consuming and expensive energy audits, 
removing key barriers for SMB owners to adopt energy retrofit technologies to improve the energy efficiency of buildings and reduce energy use and carbon emissions. An example, the retrofit of a small one story office building, highlighted the potential benefits of using DEEP. For this example, DEEP integrated with the CBES toolkit was able to provide energy retrofit feedback dependent upon input criterion (i.e. most cost-effective or most energy savings measures). Tools powered by DEEP enable quick retrofit analysis for building owners, facility managers, and engineers. DEEP can be expanded to cover more building types, more climates, and more energy conservation measures. Additionally, it can be integrated with other software tools. This resource enhances the value proposition of a retrofit assessment, promoting and accelerating voluntary retrofit actions to reduce energy use for SMB owners. Further research is needed to explore how useful DEEP is in providing actionable information to the broad community of stakeholders that it was designed for.

\section{Acknowledgement}

The establishment of DEEP was part of the Small and Medium Building Efficiency Toolkit and Community Demonstration Program funded by California Energy Commission under the Public Interest Energy Research (PIER) program (PIR-12-031). This work was also supported by the United States Department of Energy (Contract No. DE-AC02-05CH11231). The authors would like to thank the National Energy Research Scientific Computing center (NERSC) at Lawrence Berkeley National Laboratory for providing computing resource and technical support to run the EnergyPlus simulations. 


\section{References}

[1] EIA. Annual Energy Outlook 2013 with Projections to 2040. Washington DC, US: U.S. Energy Information Administration; 2013.

[2] Preservation Green Lab. Realizing the Energy Efficiency Potential of Small Buildings. Preservation Green Lab; 2013.

[3] Ma Z, Cooper P, Daly D, Ledo L. Existing building retrofits: Methodology and state-ofthe-art. Energy and Buildings 2012;55:889-902.

[4] Fluhrer C, Maurer E, Deshmukh A. Achieving radically energy efficient retrofits: The Empire State Building example. ASHRAE Transactions 2010;116:236-43.

[5] Hong T, Yang L, Hill D, Feng W. Data and Analytics to Inform Energy Retrofit of High Performance Buildings. Applied Energy 2014;126:90-106.

[6] Janda KB, Parag Y. A middle-out approach for improving energy performance in buildings. Building Research \& Information 2013;41:39-50.

[7] Roth A, Brook M, Hale ET, Ball BL, Fleming K, Long N. DEnCity : An Open MultiPurpose Building Energy Simulation Database Building Energy Simulation Datasets. ACEEE Summer Study on Energy Efficiency in Buildings, Pacific Grove, CA: 2012, p. 251-63.

[8] DOE. 179D DOE Calculator. http://apps1.eere.energy.gov/buildings/commercial/ 2014:accessed May 10, 2015.

[9] Energy Impact Illinois. EnCompass. http://encompass.energyimpactillinois.org/Default.aspx 2013:accessed April 25, 2015.

[10] Pan Y, Xu Z, Li Y. Evaluating Commercial Building Retrofit Energy Saving by Using a Building Retrofit Tool - Case Studies in Shanghai. ASim 2012, Shanghai China: 2012.

[11] IRS. Commercial Property Owners and Leaseholders Qualify for Energy Efficiency Tax Deduction. http://www.irs.gov/Businesses/Small-Businesses-\&-SelfEmployed/Commercial-Property-Owners-and-Leaseholders-Qualify-for-EnergyEfficiency-Tax-Deduction 2005:accessed April 21, 2015.

[12] NREL. Parametric Analysis Tool. Http://openstudio.nrel.gov/parametric-Analysis-ToolGetting-Started 2014:accessed May 2, 2015. 
[13] Zhang Y. "PARALLEL " EnergyPlus And The Development Of A Parametric Analysis Tool. Building Simulation, 2009, p. 1382-8.

[14] Hale E, Lisell L, Goldwasser D, Macumber D, Dean J, Metzger I, et al. Cloud-Based Model Calibration Using OpenStudio. eSim, Ottawa, Canada: 2014.

[15] Naboni, E, Zhang, Y, Maccarini, A, Hirsch, E, Lezzi D. Extending the use of parametric simulation in practice through a cloud based online service. IBPSA-Italy Conference, Bolzano, Italy: 2013.

[16] VENUS-C. VENUS-C User Communities. Http://www.venus-C.eu/ 2015:accessed April 30, 2015.

[17] Sanyal J, New J, Edwards RE, Parker L. Calibrating building energy models using supercomputer trained machine learning agents. Concurrency Computation Practice and Experience 2014;26:2122-33.

[18] Thain D, Tannenbaum T, Livny M. Distributed computing in practice: the Condor experience. Concurrency and Computation: Practice and Experience 2005;17:323-56.

[19] Petri I, Li H, Rezgui Y, Chunfeng Y, Yuce B. RESEARCH ARTICLE A HPC based cloud model for real-time energy optimisation. Enterprise Information Systems 2013.

[20] Tian W, de Wilde P. Thermal building simulation using the UKCP09 probabilistic climate projections. Journal of Building Performance Simulation 2011;4:105-24.

[21] Kim H, Parashar M. Cloud Computing: Principles and Paradigms Chapter 10: CometCloud: An Autonomic Cloud Engine. Wiley; 2010.

[22] Li Z, Parashar M. No Title. HPDC, Monterey, California, USA: 2004, p. 229-30.

[23] CEC. California Building Climate Zone Map. Http://www.energy.ca.gov/maps/renewable/building_climate_zones.html 2014:accessed April 28, 2015.

[24] CEC. Building Energy Efficiency Program. http://www.energy.ca.gov/title24/ 2014:accessed May 05, 2015.

[25] CEC. DEER - Database for Energy Efficient Resources. Http://www.energy.ca.gov/deer/ 2014:accessed May 1, 2015.

[26] DOE. Commercial Reference Buildings. Http://energy.gov/eere/buildings/commercialReference-Buildings 2015:accessed May 5, 2015. 
[27] LBNL. Software Functional Specification Requirements for California Energy Commission Small and Medium Building Efficiency Toolkit and Community Demonstration Program. LBNL; 2014.

[28] PNNL, PECI. Advanced Energy Retrofit Guide: Practical Ways to Improve Energy Performance Office Buildings. PNNL; 2011.

[29] PNNL, PECI. Advanced Energy Retrofit Guide: Practical Ways to Improve Energy Performance Retail Buildings. PNNL; 2011.

[30] CEC. Small HVAC System Design Guide 500-03-082-A12. CEC; 2003.

[31] ASHRAE. Advanced Energy Design Guide for Small to Medium Office Buildings. ASHRAE; 2011.

[32] LBNL. Home Energy Saver. Http://homeenergysaver.lbl.gov/consumer/ 2014:accessed May 1, 2015.

[33] LBNL. Efficiency Measure and Smart-Meter Data Compilation for California Energy Commission Small and Medium Building Efficiency Toolkit and Community Demonstration Program. LBNL; 2014.

[34] EPA. ENERGY STAR. Http://www.energystar.gov/ 2015:accessed May 2, 2015.

[35] LBNL. EnergyIQ Action-oriented Energy Benchmarking. Http://energyiq.lbl.gov/ 2015:accessed May 1, 2015. 


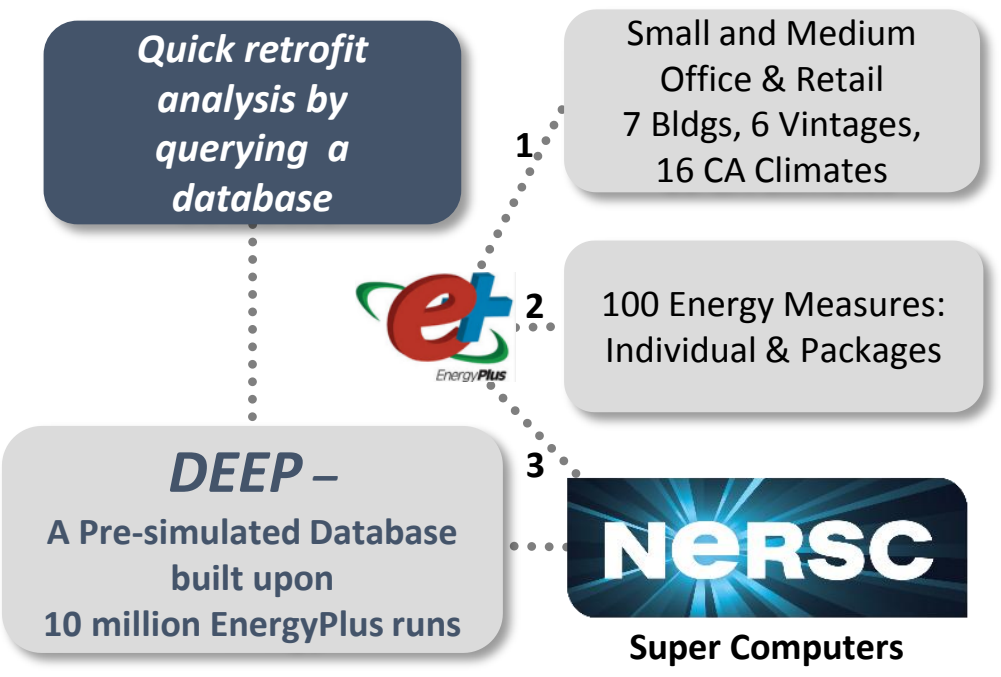

Figure 1 Overview of DEEP

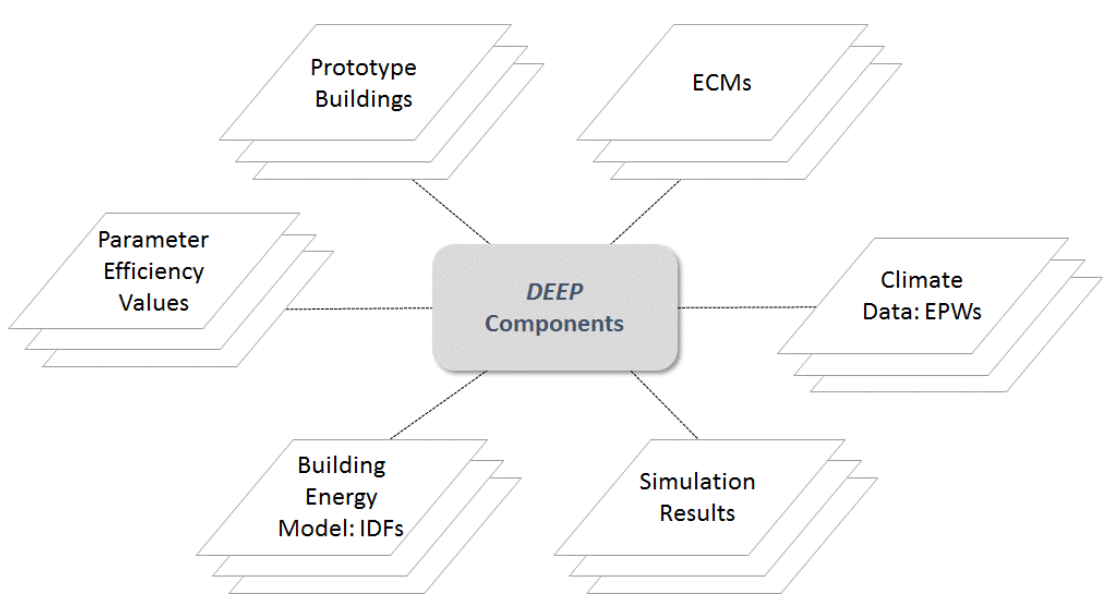

Figure 2 Components of DEEP 
1. Setup Prototype Buildings

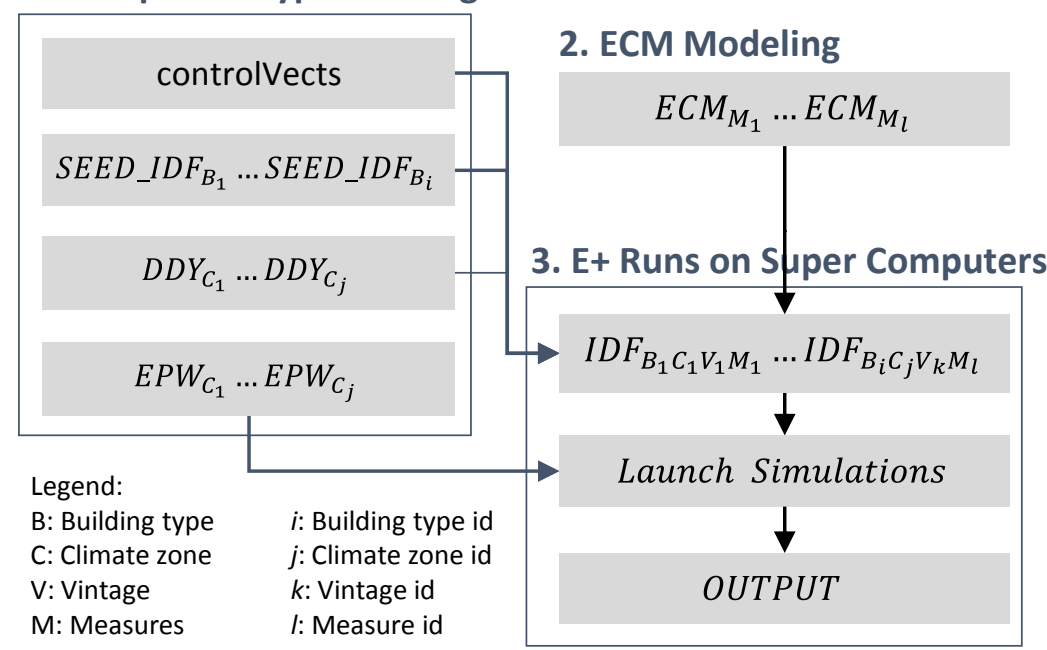

Figure 3 The framework used for establishing DEEP

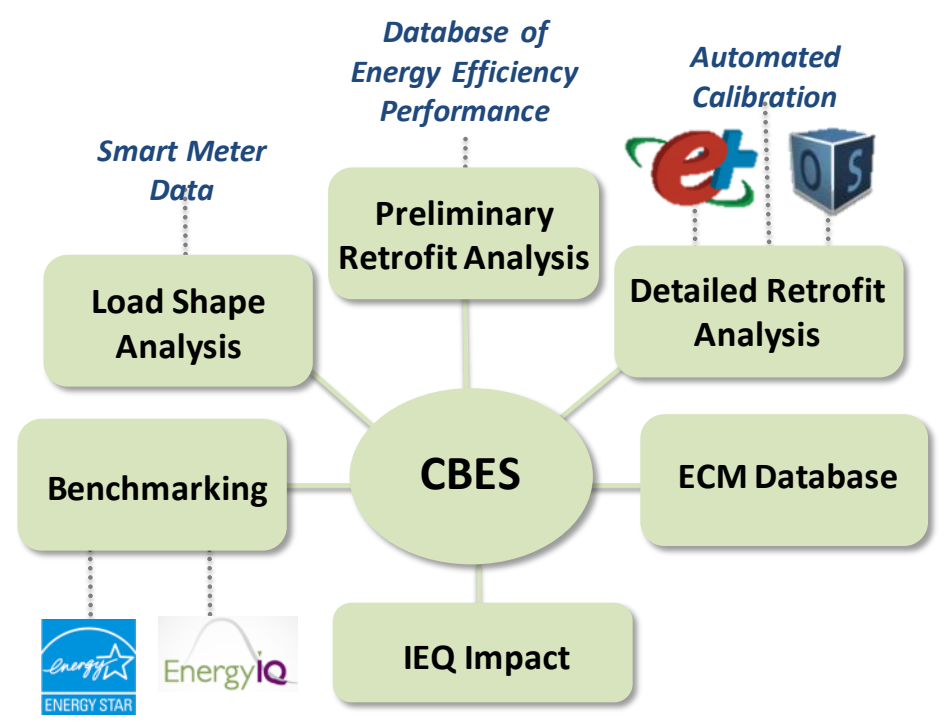

Figure 4 Features of CBES Toolkit 
Tables

Table 1 Description of the prototype buildings

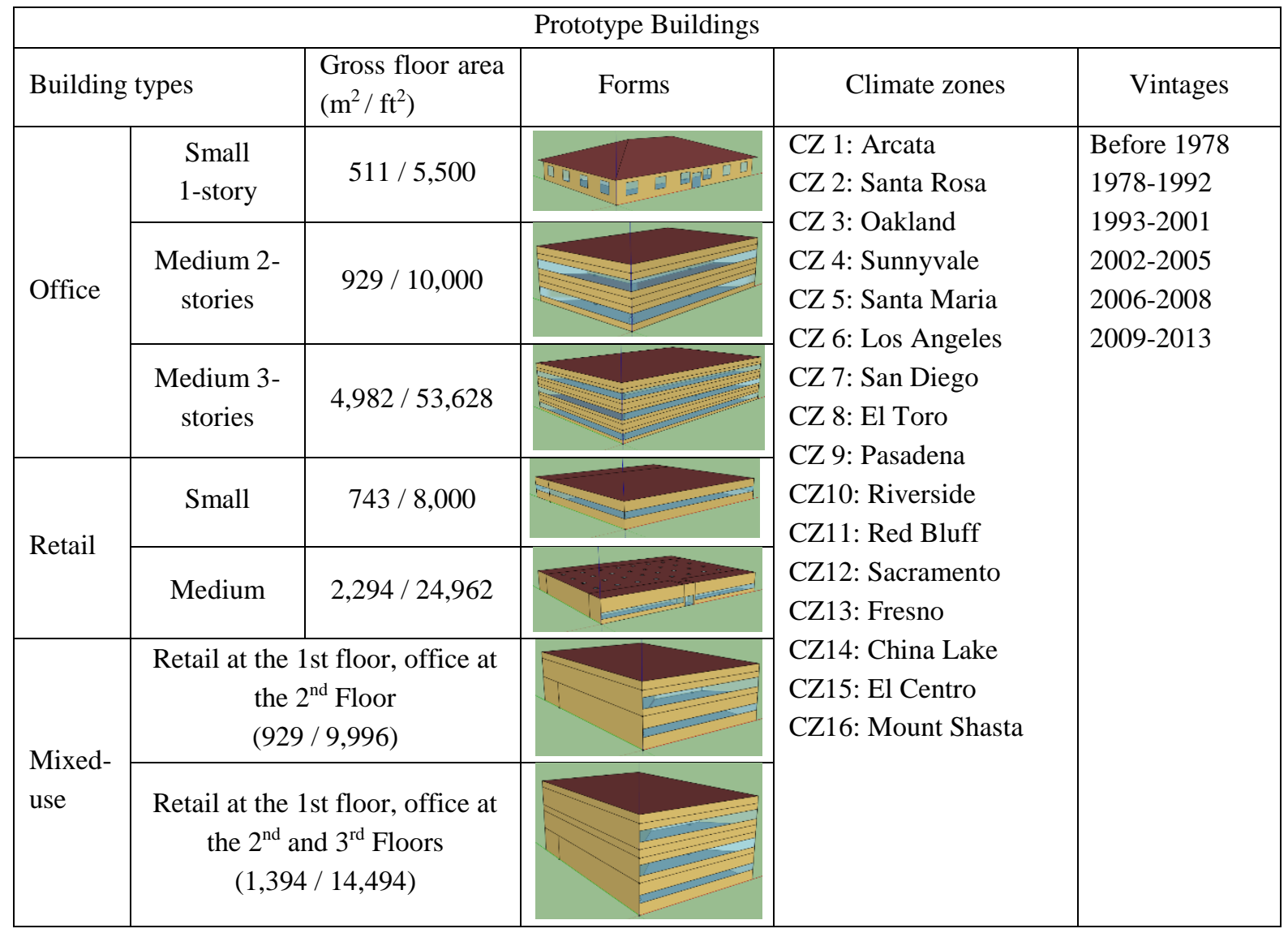


Table 2 Prototype development sources

\begin{tabular}{|c|c|c|c|}
\hline \multicolumn{2}{|c|}{ Building Type } & Sources of the Base models & Parameter sources \\
\hline \multirow{3}{*}{ Office } & $\begin{array}{c}\text { Small } \\
\text { 1-story }\end{array}$ & DOE reference model & \multirow{7}{*}{$\begin{array}{l}\text { Title 24: Non- } \\
\text { Residential } \\
\text { Alternative } \\
\text { Calculation Method } \\
\text { reference and DEER } \\
2011 \text { Version } 4.01\end{array}$} \\
\hline & $\begin{array}{l}\text { Medium 2- } \\
\text { stories }\end{array}$ & DEER & \\
\hline & $\begin{array}{l}\text { Medium 3- } \\
\text { stories }\end{array}$ & DOE reference models & \\
\hline \multirow{2}{*}{ Retail } & Small & DEER & \\
\hline & Medium & DOE reference model & \\
\hline \multirow[b]{2}{*}{ Mixed-use } & $\begin{array}{l}\text { Retail at the } \\
1 \text { st floor, } \\
\text { office at the } \\
2^{\text {nd }} \text { Floor }\end{array}$ & \multirow{2}{*}{$\begin{array}{l}\text { DOE reference model } \\
\text { (First floor: A large store unit of the strip } \\
\text { mall and Second / third floor: } \\
\text { Accompanying office space matching to the } \\
\text { first floor) }\end{array}$} & \\
\hline & $\begin{array}{l}\text { Retail at the } \\
1 \text { st floor, } \\
\text { office at the } \\
2^{\text {nd }} \text { and } 3^{\text {rd }} \\
\text { Floors }\end{array}$ & & \\
\hline
\end{tabular}

Table 3 A sample list of Title 24 efficiency requirements

\begin{tabular}{|c|c|c|c|c|c|}
\hline Vintage & $\begin{array}{l}\text { LPD }\left[\mathrm{W} / \mathrm{m}^{2}\right] \\
\text { Office / Retail }\end{array}$ & $\begin{array}{c}\text { Cooling } \\
\text { COP }\end{array}$ & $\begin{array}{c}\text { Heating } \\
\text { COP }\end{array}$ & $\begin{array}{l}\text { Windows U-Value }\left[\mathrm{W} / \mathrm{K} \cdot \mathrm{m}^{2}\right] \\
\text { Climate Zone } 1 \text { - } 16\end{array}$ & $\begin{array}{c}\text { Windows SHGC } \\
\text { Climate Zone } 1 \text { - } 16\end{array}$ \\
\hline Before 1978 & $21.39 / 30.83$ & 3.07 & 0.78 & $\begin{array}{c}6.98,6.98,6.98,6.98,6.98,6.98,6.98,6.98, \\
6.98,6.98,6.98,6.98,6.98,6.98,6.98,6.98\end{array}$ & $\begin{array}{l}0.82,0.82,0.82,0.82,0.82,0.82,0.82,0.82, \\
0.82,0.82,0.82,0.82,0.82,0.82,0.82,0.82\end{array}$ \\
\hline $1978-1992$ & $17.57 / 25.83$ & 3.39 & 0.8 & $\begin{array}{l}4.37,6.98,6.98,6.98,6.98,6.98,6.98,6.98, \\
6.98,6.98,6.98,6.98,6.98,4.37,4.37,4.37\end{array}$ & $\begin{array}{l}0.77,0.82,0.82,0.82,0.82,0.82,0.82,0.82, \\
0.82,0.82,0.82,0.82,0.82,0.77,0.77,0.77\end{array}$ \\
\hline $1993-2001$ & $12.63 / 18.51$ & 3.39 & 0.8 & $\begin{array}{l}4.37,6.98,6.98,6.98,6.98,6.98,6.98,6.98, \\
6.98,6.98,6.98,6.98,6.98,4.37,4.37,4.37\end{array}$ & $\begin{array}{c}0.50,0.62,0.62,0.62,0.62,0.62,0.62,0.62, \\
0.62,0.62,0.50,0.50,0.50,0.50,0.50,0.50\end{array}$ \\
\hline $2002-2005$ & $12.58 / 18.51$ & 3.67 & 0.8 & $\begin{array}{l}2.67,2.67,4.37,4.37,4.37,4.37,4.37,4.37 \\
4.37,2.67,2.67,2.67,2.67,2.67,2.67,2.67\end{array}$ & $\begin{array}{l}0.49,0.47,0.61,0.61,0.61,0.61,0.61,0.61, \\
0.61,0.47,0.47,0.47,0.47,0.46,0.46,0.49\end{array}$ \\
\hline $2006-2008$ & $11.84 / 16.15$ & 3.67 & 0.8 & $\begin{array}{l}2.67,2.67,4.37,4.37,4.37,4.37,4.37,4.37 \\
4.37,2.67,2.67,2.67,2.67,2.67,2.67,2.67\end{array}$ & $\begin{array}{l}0.49,0.47,0.61,0.61,0.61,0.61,0.61,0.61, \\
0.61,0.47,0.47,0.47,0.47,0.46,0.46,0.49\end{array}$ \\
\hline $2009-2013$ & $9.15 / 16.15$ & 3.67 & 0.8 & $\begin{array}{c}2.67,2.67,4.37,4.37,4.37,4.37,4.37,4.37, \\
4.37,2.67,2.67,2.67,2.67,2.67,2.67,2.67\end{array}$ & $\begin{array}{l}0.49,0.47,0.61,0.61,0.61,0.61,0.61,0.61, \\
0.61,0.47,0.47,0.47,0.47,0.46,0.46,0.49\end{array}$ \\
\hline
\end{tabular}


Table 4 A sample list of energy conservation measures

\begin{tabular}{|c|c|c|c|}
\hline Category & Component & Name & Description \\
\hline Lighting & $\begin{array}{l}\text { Interior Lighting } \\
\text { Equipment } \\
\text { Retrofit }\end{array}$ & $\begin{array}{l}\text { Replace existing lighting } \\
\text { with } \mathrm{LED} \text { upgrade } \\
\left(6.5 \mathrm{~W} / \mathrm{m}^{2}\right)\end{array}$ & $\begin{array}{l}\text { Replace existing lighting to LEDs with } 6.5 \mathrm{~W} / \mathrm{m}^{2} \\
{\left[2.38 \mathrm{Btu} / \mathrm{h} / \mathrm{ft}^{2} \text {. LEDs consume less power and last }\right.} \\
\text { longer than fluorescent lamps. A retrofit kit is } \\
\text { recommended for converting ballasts. Replacement } \\
\text { may improve lighting quality. }\end{array}$ \\
\hline Plug Loads & $\begin{array}{l}\text { Equipment } \\
\text { Control }\end{array}$ & $\begin{array}{l}\text { Use Plug Load Controller } \\
(30 \% \text { efficient from } \\
\text { Baseline) }\end{array}$ & $\begin{array}{l}\text { Connect plug loads to a smart plug strip with some } \\
\text { or all of the following functions: Occupancy } \\
\text { sensing, load sensing, timers, remote control. }\end{array}$ \\
\hline $\begin{array}{l}\text { Envelope - } \\
\text { Exterior } \\
\text { Wall }\end{array}$ & Exterior Wall & $\begin{array}{l}\text { Apply Wall Insulation } \\
\text { (R21) }\end{array}$ & $\begin{array}{l}\text { Apply blown-fiberglass insulation (R21) to wall } \\
\text { cavity will help maintain the thermal comfort. } \\
\text { Insulation provides resistance to heat flow, taking } \\
\text { less energy to heat/cool the space. }\end{array}$ \\
\hline $\begin{array}{l}\text { Envelope - } \\
\text { Roof }\end{array}$ & Roof & $\begin{array}{l}\text { Reroof and Roof with } \\
\text { Insulation }\end{array}$ & $\begin{array}{l}\text { Demolish existing roof, install insulation (R24.83) } \\
\text { and reroof to reduced unwanted heat gain/loss. This } \\
\text { measure is most applicable to older roofs. }\end{array}$ \\
\hline $\begin{array}{l}\text { Envelope - } \\
\text { Window }\end{array}$ & Window & $\begin{array}{l}\text { Replace fixed-window to } \\
\text { U-factor }(0.25) \text { and } \\
\text { SHGC }(0.18)\end{array}$ & $\begin{array}{l}\text { Replace existing window glass and frame with high } \\
\text { performance windows by changing the U-factor and } \\
\text { SHGC of the window material. The U-factor is a } \\
\text { measure of thermal transmittance and SHGC stands } \\
\text { for Solar Heat Gain Coefficient, values taken as } 1.42 \\
\mathrm{~W} /\left(\mathrm{K} \cdot \mathrm{m}^{2}\right)\left[0.25 \mathrm{Btu} /\left(\mathrm{h} \cdot \mathrm{ft}^{2} \cdot{ }^{\circ} \mathrm{F}\right)\right] \text {, SHGC: } 0.18 \text {. The } \\
\text { SHGC and U-factor are } 30 \% \text { below Title } 24 \text { values. }\end{array}$ \\
\hline $\begin{array}{l}\text { Service Hot } \\
\text { Water }\end{array}$ & Storage Tank & $\begin{array}{l}\text { Efficiency Upgrade of the } \\
\text { Gas Storage Water Heater }\end{array}$ & $\begin{array}{l}\text { Replace the existing service hot water heater with } \\
\text { more efficient gas storage unit, with better } \\
\text { insulation, heat traps and more efficient burners to } \\
\text { increase overall efficiency of }(0.93) \text {. }\end{array}$ \\
\hline $\begin{array}{l}\text { HVAC - } \\
\text { Cooling }\end{array}$ & Cooling System & $\begin{array}{l}\text { Packaged Rooftop VAV } \\
\text { Unit Efficiency Upgrade } \\
\text { (SEER 14) }\end{array}$ & $\begin{array}{l}\text { Replace RTU with higher-efficiency unit with reheat, } \\
\text { SEER 14. Cooling only; include standard controls, } \\
\text { curb, and economizer. }\end{array}$ \\
\hline $\begin{array}{l}\text { HVAC - } \\
\text { Economizer }\end{array}$ & Ventilation & Add Economizer & $\begin{array}{l}\text { Install economizer for existing HVAC system } \\
\text { (includes temperature sensors, damper motors, } \\
\text { motor controls, and dampers). Typically an } \\
\text { economizer is a heat exchanger used for preheating. }\end{array}$ \\
\hline $\begin{array}{l}\text { Envelope - } \\
\text { Infiltration }\end{array}$ & Infiltration & $\begin{array}{l}\text { Add Air Sealing to Seal } \\
\text { Leaks }\end{array}$ & $\begin{array}{l}\text { Air sealing can reduce cold drafts and help improve } \\
\text { thermal comfort in buildings. Air sealing is a } \\
\text { weatherization strategy which will change the air } \\
\text { exchange rate and IAQ. }\end{array}$ \\
\hline
\end{tabular}


Table 5 Constituents used in creating the total number of simulation runs

\begin{tabular}{|l|l|}
\hline Number & Description \\
\hline 672 & Prototype buildings (7 building types, 6 vintages, and 16 climate zones) \\
\hline 24,256 & Baseline buildings with upgrades allowing combinations \\
\hline 536,992 & Retrofits (applied to the baseline buildings) from individual measures \\
\hline $8,470,384$ & $\begin{array}{l}\text { Retrofits (applied to the baseline buildings) from packages of measures with } \\
\text { combination of selected measures (with more attractive energy savings or energy } \\
\text { cost reductions) }\end{array}$ \\
\hline
\end{tabular}

Table 6 Input parameters for the CBES toolkit benchmarking and Level 2 analysis

\begin{tabular}{cc}
\hline Input Variable & Description \\
\hline Building type & 1-story office building \\
Zip code & 94127 \\
Year built & 1977 \\
Gross floor area & $7,500 \mathrm{ft}^{2}\left(697 \mathrm{~m}^{2}\right)$ \\
Total investment & $\$ 15,000$ \\
Payback period & $<3$ years \\
Previous lighting & from 2.0 to $1.1 \mathrm{~W} / \mathrm{ft}^{2}\left(21.5\right.$ to $\left.11.8 \mathrm{~W} / \mathrm{m}^{2}\right)$ \\
upgrade & \\
\hline
\end{tabular}


Table 7 Monthly electricity and natural gas usage

\begin{tabular}{ccc}
\hline Month & $\begin{array}{c}\text { Electricity } \\
{[\mathrm{kWh}]}\end{array}$ & $\begin{array}{c}\text { Natural } \\
\text { Gas }[\mathrm{kWh}]\end{array}$ \\
\hline January & 10,223 & 1,170 \\
February & 9,156 & 732 \\
March & 10,568 & 619 \\
April & 9,501 & 528 \\
May & 10,162 & 286 \\
June & 10,178 & 230 \\
July & 10,118 & 164 \\
August & 10,881 & 180 \\
September & 10,362 & 180 \\
October & 10,213 & 335 \\
November & 9,825 & 692 \\
December & 10,043 & 1,080 \\
\hline & & \\
\hline
\end{tabular}


Table 8 CBES Level 2 Preliminary Retrofit Analysis Results using DEEP

Description of measures

\begin{tabular}{|c|c|c|c|c|c|}
\hline $\begin{array}{c}\text { Measur } \\
\text { e ID }\end{array}$ & Category & Name & IEQ Impact & $\begin{array}{l}\text { Cost } \\
\text { Unit }\end{array}$ & $\begin{array}{l}\text { Total } \\
\text { cost } \\
\text { per } \\
\text { Unit }\end{array}$ \\
\hline ECM 1 & Lighting & $\begin{array}{c}\text { Replace } \\
\text { existing lighting } \\
\text { with T8 } \\
\text { upgrade } \\
(0.7 \mathrm{~W} / \mathrm{sf})\end{array}$ & $\begin{array}{l}\text { Lighting conditions can affect occupant satisfaction and } \\
\text { may affect work performance. Lighting upgrades need to } \\
\text { provide adequate illumination and accessible control. }\end{array}$ & $\$ / s f$ & 0.63 \\
\hline ECM 12 & $\begin{array}{c}\text { HVAC - } \\
\text { Economizer }\end{array}$ & $\begin{array}{l}\text { Add } \\
\text { Economizer }\end{array}$ & $\begin{array}{c}\text { Adding an economizer will increase outside air } \\
\text { ventilation and can improve indoor air quality. In office } \\
\text { settings, studies found that more outside air can reduce } \\
\text { sick building syndrome (SBS) symptoms and improve } \\
\text { work performance. Similar benefits may also apply to } \\
\text { retail and mixed-use buildings }\end{array}$ & $\$ /$ ton & 387 \\
\hline ECM 15 & Plug Loads & $\begin{array}{l}\text { Use Plug Load } \\
\text { Controller } \\
\text { (30\% efficient } \\
\text { from Baseline) }\end{array}$ & 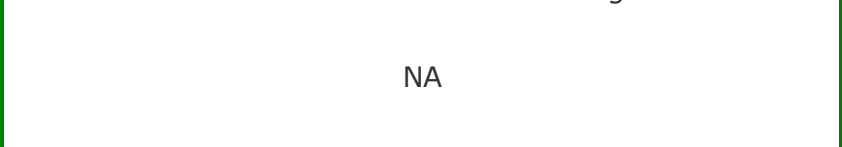 & $\$ / s f$ & 0.8 \\
\hline
\end{tabular}

Annual site energy and $\mathrm{CO2}$ emissions

\begin{tabular}{|c|c|c|c|c|c|c|}
\hline & Measure ID(s) & $\begin{array}{c}\text { Electricity } \\
\quad(k W h)\end{array}$ & $\begin{array}{c}\text { Natural Gas } \\
\text { (therm) }\end{array}$ & $\begin{array}{c}\text { Electricity } \\
\text { Demand } \\
\text { Charge (\$) }\end{array}$ & $\begin{array}{c}\text { Energy Cost } \\
\text { (\$) }\end{array}$ & $\begin{array}{c}\text { CO2 Emission } \\
\text { (lbs) }\end{array}$ \\
\hline 0 & Baseline & 84,876 & 648 & 873 & 15,766 & 66,232 \\
\hline 1 & ECM $12 ; 15$ & 67,767 & 688 & 750 & 12,810 & 54,954 \\
\hline 2 & ECM $12 ; 1$ & 68,127 & 691 & 760 & 12,883 & 55,232 \\
\hline 3 & ECM 1 & 75,011 & 695 & 784 & 14,068 & 60,022 \\
\hline 4 & ECM 12 & 76,764 & 640 & 847 & 14,369 & 60,557 \\
\hline
\end{tabular}

Annual economic analysis

\begin{tabular}{|c|c|c|c|c|c|c|c|c|c|}
\hline & $\begin{array}{c}\text { Measure } \\
I D(s)\end{array}$ & $\begin{array}{l}\text { Energy } \\
\text { Cost } \\
\text { Savings } \\
\text { (\$) }\end{array}$ & $\begin{array}{c}\text { Energy } \\
\text { Savings } \\
(k W h)\end{array}$ & $\begin{array}{c}\text { Electricity } \\
\text { Cost } \\
\text { Savings } \\
\text { (\$) }\end{array}$ & $\begin{array}{c}\text { Electricity } \\
\text { Savings } \\
\text { (kWh) }\end{array}$ & $\begin{array}{c}\text { Natural } \\
\text { Gas Cost } \\
\text { Savings } \\
\text { (\$) }\end{array}$ & $\begin{array}{l}\text { Natural } \\
\text { Gas } \\
\text { Savings } \\
\text { (therm) }\end{array}$ & $\begin{array}{c}\text { Investme } \\
\text { nt Cost } \\
\text { (\$) }\end{array}$ & $\begin{array}{c}\text { Payback } \\
\text { (Year) }\end{array}$ \\
\hline 1 & ECM $12 ; 15$ & 2,956 & 15,923 & 2,873 & 17,109 & -40 & -40 & 8,697 & 2.9 \\
\hline 2 & ECM $12 ; 1$ & 2,882 & 15,490 & 2,812 & 16,749 & -43 & -43 & 7,450 & 2.6 \\
\hline 3 & ECM 1 & 1,698 & 8,472 & 1,656 & 9,865 & -47 & -48 & 4,740 & 2.8 \\
\hline 4 & ECM 12 & 1,396 & 8,341 & 1,362 & 8,112 & 8 & 8 & 2,612 & 1.9 \\
\hline
\end{tabular}

Measure ID(s) with $\left(^{*}\right)$ means the retrofit option does not meet the investment criteria.

Annual energy and cost saving percentage

\begin{tabular}{|c|c|c|c|c|c|}
\hline & Measure ID(s) & $\begin{array}{c}\text { Energy Cost } \\
\text { Savings(\%) }\end{array}$ & $\begin{array}{c}\text { Energy Savings } \\
(\%)\end{array}$ & $\begin{array}{c}\text { Electricity } \\
\text { Usage/Cost Savings } \\
(\%)\end{array}$ & $\begin{array}{c}\text { Natural Gas } \\
\text { Usage/Cost Savings } \\
(\%)\end{array}$ \\
\hline 1 & ECM $12 ; 15$ & $18.70 \%$ & $15.30 \%$ & $20.20 \%$ & $-6.20 \%$ \\
2 & ECM $12 ; 1$ & $18.30 \%$ & $14.90 \%$ & $19.70 \%$ & $-6.60 \%$ \\
3 & ECM 1 & $10.80 \%$ & $8.20 \%$ & $11.60 \%$ & $-7.30 \%$ \\
4 & ECM 12 & $8.90 \%$ & $8.00 \%$ & $9.60 \%$ & $1.20 \%$
\end{tabular}

